BOLETIN LATINOAMERICANO Y DEL CARIBE DE PLANTAS MEDICINALES Y AROMÁTICAS

19 (6): 542 - 554 (2020)

○ / ISSN 07177917 / www.blacpma.ms-editions.cl

\title{
Articulo Invitado / Invited Article \\ Effect of encephalomyocarditis virus 3'Untranslated region on GFP transient expression: implications in recombinant protein production
}

[Efecto de la Región 3'-no traducida del virus de la encefalomiocarditis sobre la expresión transitoria de GFP: implicaciones en la producción de proteínas recombinantes]

\author{
Marzieh Marzbany ${ }^{1} \&$ Mahsa Rasekhian² \\ ${ }^{1}$ Pharmacognosy and Pharmaceutical Biotechnology Group, School of Pharmacy, Kermanshah University of Medical Sciences, \\ Kermanshah, Iran \\ ${ }^{2}$ Pharmaceutical Sciences Research Center, Health Institute, Kermanshah University of Medical Sciences, Kermanshah, Iran \\ Contactos | Contacts: Mahsa RASEKHIAN - E-mail address: mahsarasekhian@gmail.com
}

\begin{abstract}
The enrichment of therapeutic protein production yield in mammalian cell cultures by modulating mRNA stability is a fairly new strategy in biotechnological applications. Here, we describe the application of $3^{\prime}$-untranslated region (3'UTR) from RNA viral genome to modulate mRNA stability. The data obtained showed that the use of the 3 'UTR sequence of the encephalomyocarditis virus (EMCV 3'UTR) downstream of the target gene was not able to significantly modulate the free energy density indicators of the RNA. However, the sequence influenced the stability of the mRNA (and, therefore, the amount of protein production) in a cell type and time-dependent manner, indicating a central role of mRNA-stabilizing binding sites/cellular factors in this process. Our data might be of interest for the biotechnology community to improve recombinant protein production in mammalian cell cultures and RNA-based therapy/vaccination approaches.
\end{abstract}

Keywords: Biopharmaceuticals; 3’UTR; EMCV; Positive sense genome

Resumen: El enriquecimiento de la producción terapéutica de proteínas en cultivos de células de mamíferos mediante la modulación de la estabilidad del ARNm es una estrategia nueva en aplicaciones biotecnológicas. Se describe la aplicación de la región 3'-no traducida (3'UTR) del genoma viral ARN para modular la estabilidad del ARNm. Los datos obtenidos mostraron que el uso de la secuencia 3 'UTR del virus de la encefalomiocarditis (EMCV 3'UTR) aguas abajo del gen objetivo no pudo modular significativamente los indicadores de densidad de energía libre del ARN. Sin embargo, la secuencia influyó en la estabilidad del ARNm (y, por lo tanto, en la cantidad de producción de proteínas) dependiente de la célula y del tiempo, lo que indica un papel central de los sitios de unión estabilizadores de ARNm/factores celulares en este proceso. Nuestros datos podrían ser de interés para la comunidad biotecnológica para mejorar la producción de proteínas recombinantes en cultivos de células de mamíferos y en enfoques de terapia/vacunación basados en ARN.

Palabras clave: Productos biofarmacéuticos; 3'UTR; EMCV; Genoma sentido positivo

Recibido | Received: May 6, 2020

Aceptado | Accepted: June 8, 2020

Aceptado en versión corregida | Accepted in revised form: June 11, 2020

Publicado en línea | Published online: November 30, 2020

Este artículo puede ser citado como / This article must be cited as: M Marzbany, M Rasekhian. 2020. Effect of encephalomyocarditis virus 3'Untranslated region on GFP transient expression: implications in recombinant protein production. Bol Latinoam Caribe Plant Med Aromat 19 (6): 542 - 554. https://doi.org/10.37360/blacpma.20.19.6.38 


\section{INTRODUCTION}

Recombinant DNA technology is acquiring a vital role in improving health conditions by allowing the development of new vaccines and biopharmaceuticals. Under this technology, essential proteins required for health problems can be produced safely, affordably, and sufficiently. In recombinant DNA technology, the genetic material of different species are joint together and is, then, transfected (inserted) into a host organism to produce new genetic combinations that are valuable to medicine (Khan et al., 2016).

Introduced genetic materials (DNAs and RNAs) exist in cells either stably or transiently depending on the nature of the genetic materials. For stable transfection, introduced genetic materials that generally have a marker gene for selection (transgenes) integrate into the host genome and maintain transgene expression even after host cells replicate. Unlike stably transfected genes, transiently transfected genes are only expressed for a limited time and are not integrated into the genome. Traditionally, mammalian expression systems rely on the time-consuming generation of stable cell lines (Kim \& Eberwine, 2010). However, in the development of medically active proteins, time to market is a critical cost factor. Therefore, tools such as transient gene expression systems that provide research or clinical grade material more rapidly are valuable (Girard et al., 2002; Kim \& Eberwine, 2010; Bassani et al., 2014).

The 3 'terminal noncoding elements of genes comprising the $3^{\prime}$ untranslated regions ( $3^{\prime} \mathrm{UTR}$ ) of mRNA perform essential regulatory functions at the posttranscriptional and translational levels of eukaryotic gene expression. With their start being at the translation termination codon, these sequences are involved in mRNA processing, they control mRNA stability and localization of the transcripts in cells, and influence the rate of translation. Studies on 3'UTR in eukaryotic cells show the diversity of their sequences and their length. This diversity indicates the importance of these sequences in determining the post-transcription modification (Jin et al., 2018). The 3'UTRs are among the primary targets of regulatory microRNAs (miRNAs) and can inhibit translation of relevant mRNAs. In general, longer 3'UTRs associate with a lower level of translation of their mRNA, derived from the presence of a more significant number of miRNA binding sites in their sequence. For example, some mRNA isoforms, such as transcripts of the Hip2 gene, use alternative 3'UTRs of varying length that differ in the number of miRNA binding sites (Petrushev \& Kovalenko, 2014).

The stability of mRNAs is an essential aspect of gene regulation since it influences the overall cellular mRNA concentration. Cis-regulatory elements mRNA itself (CRE) encode mRNA stability in a gene. CREs comprise, among others secondary structures, the sequence motifs present in the 3' UTR including binding sites of RNA-binding proteins (RBP), and, in higher eukaryotes, miRNAs (Cheng et al., 2017).

RNA viruses carry their entire life cycle in the cytoplasm and require a significant number of copies of their genomes to establish an infection. This is while the cytoplasm of the eukaryotic cells is regularly checked by RNA surveillance machinery to eliminate damaged RNA. Therefore, naturally, these types of viruses have been equipped with mechanisms to protect their genetic material during evolution. The crucial participation of cellular RNA-binding proteins (RBPs) in virtually all steps of virus infection has been known for decades (GarcíaMoreno et al., 2018). The encephalomyocarditis virus (EMCV) is the causative agent of not only myocarditis and encephalitis, but also neurological diseases, reproductive disorders and diabetes in many mammalian species. The EMCV, like other picornaviruses, is a small non-enveloped virus, with an icosahedral capsid of $30 \mathrm{~nm}$ diameter10 and a genome consisting of a positive single-stranded RNA of approximately $7.8 \mathrm{~kb}$ that allows direct translation of the RNA into a polyprotein. Viral RNA acts as an mRNA during translation and as a template during genome replication. The genome has a unique coding region flanked by 5' and 3'UTRs. The 5' UTR is between 800 to 1,200 nucleotides (nt) long, while the $3^{\prime}$ UTR is about $120 \mathrm{nt}$ long and composed of short stem-loop structures followed by a poly(A) tail of variable length (20 to $70 \mathrm{nt}$ ) (Fields \& Knipe, 1991).

In the present study, we sought to find out whether the addition of the EMCV 3'UTR sequence to the end of the EGFP reporter gene could affect its expression and whether this effect is due to the stability of mRNA.

\section{MATERIAL AND METHODS Selection of sequence data set}

All the EMCV strains with a complete genome sequence were extracted from www.ncbi.nlm.nih.gov website for National Centre for Biotechnology Information. A total of 21 complete genomes were selected and an alignment was created by CLC Main 
Workbench software (version b5.5). Based on the alignment results, 3'UTR sequence of EMCV NC_001479 strain, (122 nucleotide sequence (77137835) of the 3'UTR of NC_001479 strain) was chosen for chemical synthesis (General Biotech Co., Ltd.).

\section{Plasmid design and synthesis}

EGFP sequence was amplified using specific PCR primers and pEGFPN-1 plasmid as a template. pwo DNA polymerase was used to amplify the sequence. Amplified sequence was cloned into EcoRV restriction site of pcDNA 3.1(-) ${ }^{\mathrm{TM}}$ vector following standard protocols (Green \& Sambrook, 2012). This plasmid was called (-3UTR) and was used as a reference sample for the calculation of relative expression of EGFP (Livak \& Schmittgen, 2001). The selected sequence of the 3'UTR of EMCV was ordered for chemical synthesis (GLBiochem, Shanghai, China). Recognition sites for EcoRI and BamHI restriction sites were added to the 5' and 3' ends of the sequence. These sequence was primarily cloned in pUC57 by the manufacturer and then subcloned into (-3UTR) vector by EcoRI and BamHI restriction enzymes. The resulting plasmid was called (+3UTR) and was used as the target sample for calculation of relative expression of EGFP (Figure No. 1). The accuracy of recombinant plasmids was confirmed by restriction enzyme analysis and sequencing (data not shown).

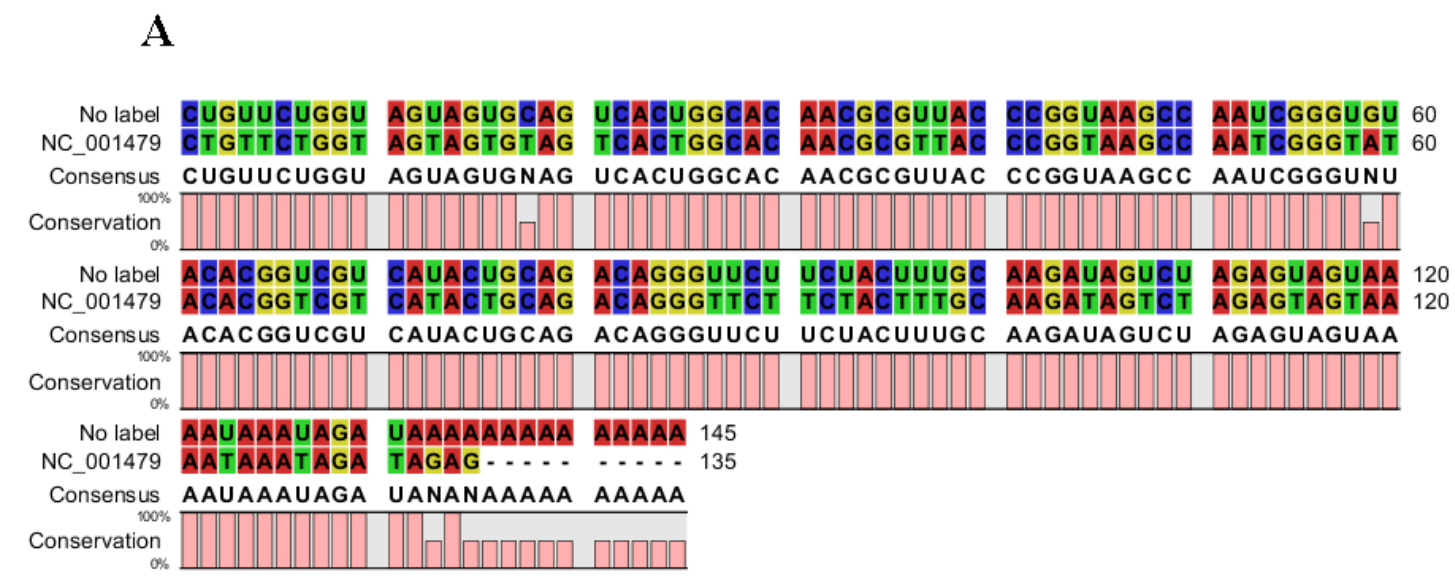

B
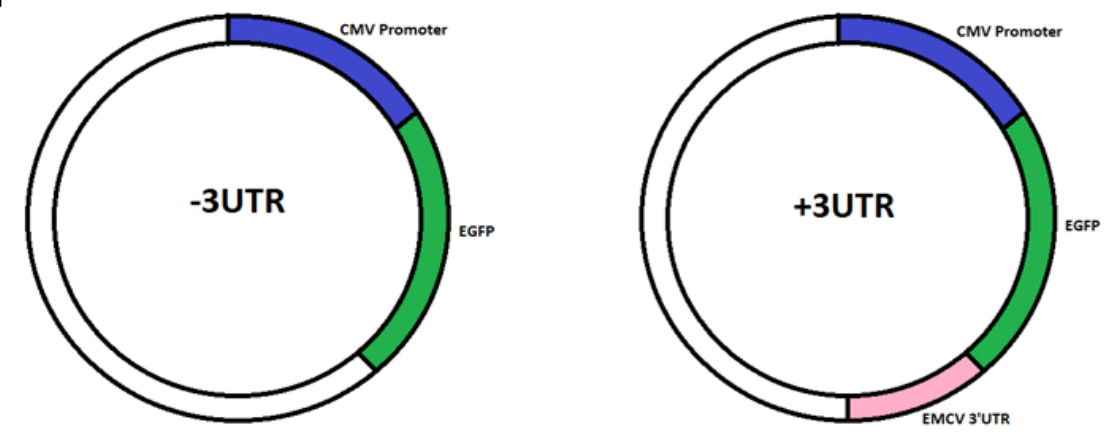

Figure No. 1

A) sequence alignment of 3'UTR sequences of EMCV NC_001479 and Consensus sequence. 3' UTR sequences of 21 submitted EMCV were extracted from NCBI and aligned using CLC main workbench. A consensus sequence was extracted after their alignment. The consensus sequence was then used to creat an alignment with 3'UTR of NC_001497. (-)represent gaps. B) extracted sequence was then used construct +3UTR plasmid 


\section{Analysis of EMCV 3'UTR for known RNA Binding Proteins interactions}

Search for the presence of any previously described motifs with known RNA stability modulating effects or binding sites for RNA Binding Proteins (RBP) in the 3'UTR sequence of EMCV was carried out based on the available data and analysis by RBPDB: The database of RNA-binding specificities

(http://rbpdb.ccbr.utoronto.ca/).

\section{Analysis of EMCV 3'UTR for known miRNA interactions}

Search for the presence of any previously described miRNA binding site in the 3'UTR sequence of EMCV was based on the available data and analysis by ViTa (http://vita.mbc.nctu.edu.tw).

\section{Prediction of RNA Secondary Structure}

The prediction of the possible folding of EGFP mRNA transcribed from -3UTR or +3UTR constructs was carried out based on Minimum Free Energy (MFE) with the online

http://rna.tbi.univie.ac.at/cgibin/RNAWebSuite/RNAfold.cgi

(Gruber et al., 2015).

The DNA sequences were selected from initiation point of the transcription $(+1 \mathrm{nt})$ of putative CMV promoter of pcDNA3.1 (-) ${ }^{\mathrm{TM}}$ vector to its putative polyA signal including the respective insert sequence. Calculated MFE was subsequently used to obtain the Free energy density indicator (Adjusted minimum free energy (AMFE)), dividing MFE by the length of sequence. The results were then multiplied by 100 to relate the index to a segment of 100 nucleotides (Freyhult et al., 2005).

\section{Cell lines and transfection}

BHK (Baby hamster kidney) and CHO DG44 (Chinese hamster ovary) cell lines (purchased from the Pasteur Institute of Iran), usually used for expression of various recombinant proteins, were cultured in DMEM/F12 medium supplemented with $10 \%$ bovine calf serum, $100 \mathrm{U} / \mathrm{mL}$ penicillin and 100 $\mu \mathrm{g} / \mathrm{ml}$ streptomycin. Cells were maintained at $37^{\circ} \mathrm{C}$ in a humidified incubator with $5 \% \mathrm{CO}_{2}$. After the desired confluency was reached, cells were gently washed with $1 \mathrm{X}$ PBS, detached with trypsin and plated in 24-well plates. All transfection procedures were carried out by Effectene Transfection Reagent (qiagen ${ }^{\mathrm{TM}}$ ) according to the manufacturer's protocol. Briefly, the day before transfection $5 \times 10^{5}$ cells was seeded in 24 well cell culture plates to achieve $80 \%$ of confluency at the day of transfection. At the proper confluency, cells where transfected with $200 \mathrm{ng}$ of either -3UTR or +3UTR. All transfection experiments were carried out in triplicate. Transfected cells were maintained at $37^{\circ} \mathrm{C}$ in a humidified incubator supplemented with $5 \% \mathrm{CO}_{2}$.

\section{$R N A$ extraction and EGFP relative expression assay}

24 hours after the transfection, cells were evaluated for EGFP expression by fluorescent microscopy. In order to stop transcription, cells were covered with an overlay of culture media containing $5 \mu \mathrm{g}$ ActinomycinD (Sigma-Aldrich). Subsequently, total RNA was extracted by RNeasy kit (Qiagen) according to the manufacturer protocol at $0,2,4,6,8$, 12 and 24 hour time intervals after ActinomycinD treatment. RNA concentration was assessed at 260 nanometer and ratio of 260/280 OD was used as an indicator for RNA quality (NanoDrop ${ }^{\mathrm{TM}}$ 2000/2000c Spectrophotometers - Thermo Fisher Scientific). To avoid any potential DNA contamination all RNA samples were subjected to DNase I treatment (Thermoscientific) for 45 minutes at $37^{\circ} \mathrm{C}$. DNase I was further inactivated by heat $\left(65^{\circ} \mathrm{C}\right.$ for 15 minutes $)$. All real time PCR analyses were carried out using Rotor Gene 6000 system (Corbett Research, Australia). Briefly, 20 ul reactions mixtures were set up using Power SYBR ${ }^{\circledR}$ Green RNA-to-CT ${ }^{\text {TM }}$ 1-Step Kit (Thermoscientific) containing $10 \mathrm{ng}$ of the extracted RNA as template. Samples were normalized with the control housekeeping gene "GAPDH". Relative expression levels were calculated using the $2^{-(\Delta \Delta}$ (CT)) method (Livak \& Schmittgen, 2001). All PCR analysis were carried out in triplicate.

\section{Flow cytometry and fluorescence microscopy analyses}

24 hours after transfection, cells were screened for EGFP expression via inverted fluorescent microscopy INVERSO TC100 Epi Fluor (Medline Scientific, UK). For evaluation of translation efficiency, cells were washed two times with PBS, detached with trypsin and analyzed by a flow cytometer CyFlow (Partec GmbH, Germany) equipped with FloMax@ software, version 2.7 (Quantom Analysis $\mathrm{GmbH}$, Germany). The mean fluorescence intensity (MFI) of the FL1 channel in transfected cells indicated the translation efficiency of translation. 


\section{Statistical analysis}

Data were analyzed with the SPSS statistical package (16.0 Version). All data are expressed as mean \pm standard deviation (SD) unless otherwise mentioned. Factorial analysis of variances and Student's t-test were applied for statistical analysis when appropriate. $p$ values less than 0.05 were considered significant.

\section{RESULTS}

Homology between 3'UTR of EMCV NC_001479 strain and the consensus sequence

The consensus sequence had more than $97 \%$ homology with 3'UTR sequence of EMCV NC_001479 strain. Based on the alignment that was created by CLC, a $137 \mathrm{nt}$ length consensus nucleotide sequence (immediately after the TAG stop codon) was chosen as the 3'UTR of EMCV (Figure No. 1).

\section{EMCV 3'UTR is a predicted target for RBPs and miRs}

The analysis of the 3'UTR EMCV sequence mRNA (NC_001479, nt 7713-7835) for known RNA binding proteins in RBPDB based on position weight matrices (PWMs) showed that ZRANB2 (protein 2 containing the zinc finger Ran binding domain) and RBMY1A1 (RNA-binding protein, Y-linked, family 1 , member A1) are the main successes for interaction with the designed RNA sequence. The relative score (the percent of score obtained corresponding to the possible maximum PWM score) for ZRANB2 and RBMY1A1communication were $81 \%$ and $88 \%$, respectively (Table No. 1).

Table No. 1

Score and matching sequence of RBPs with possible interaction with 3'UTR sequence of EMCV mRNA (http://rbpdb.ccbr.utoronto.ca)

\begin{tabular}{|l|l|l|l|l|l|}
\hline Score & Relative score & RBP name & start & end & $\begin{array}{l}\text { Matching } \\
\text { sequence }\end{array}$ \\
\hline 8.39364902 & $81 \%$ & ZRANB2 & 30 & 35 & CGGUAA \\
\hline 7.65633614 & $88 \%$ & RBMY1A1 & 16 & 20 & CACAA \\
\hline
\end{tabular}

Further investigation conducted by the ViTa webbased service showed that EMCV 3'UTR is an intended target for hsa- miR-339-5p and hsa-miR151-3p (Table No. 2).

Table No. 2

Score and matching sequence of miRs with possible interaction with 3'UTR sequence of EMCV mRNA (http://vita.mbc.nctu.edu.tw/)

\begin{tabular}{|c|c|c|c|c|}
\hline miR name & $\begin{array}{l}\text { Target } \\
\text { location }\end{array}$ & Mfe & $\begin{array}{l}\text { Scor } \\
\text { e }\end{array}$ & Hybridization \\
\hline $\begin{array}{l}\text { hsa-miR- } \\
\text { 339-5p }\end{array}$ & $7768-7787$ & -15 & 162 & $\begin{array}{l}\text { acucgAGGACCUCCUGUCCCu } \\
\mid \text { | || | ||||||| } \\
\text { cgtcaTACTGCA-GACAGGGt }\end{array}$ \\
\hline $\begin{array}{l}\text { hsa-miR- } \\
151-3 p\end{array}$ & 7779-7813 & -17.3 & 140 & $\begin{array}{l}\text { ggaGUUCCUCGAAG----------UCAGAUCa } \\
\|:\| \mid\|\| \| \\
\text { agaCAGGGTTCTTCTACTTTGCAAGATAGTCTAGa }\end{array}$ \\
\hline
\end{tabular}

Secondary structure prediction did not show a significant difference between thermodynamic ensemble of +3 UTR and $-3 U T R$

Thermodynamic analyses based on MFE calculations for optimal secondary structures of $+3 \mathrm{UTR}$ and -3UTR mRNA (Figure No. 2) reported $\Delta \mathrm{G}$ values of $-294.50 \mathrm{kcal} / \mathrm{mol}$ and $-257.70 \mathrm{kcal} / \mathrm{mol} \mathrm{MFE}$, respectively. To normalize the predicted $\Delta \mathrm{G}$ to the length of mRNA, $\Delta \mathrm{G}$ was divided by the number of nucleotides in the sequence; 867 and 732 for +3 UTR and -3UTR, respectively. The results showed that free energy density indicators are equivalent to 34 and 35 for +3 UTR and -3UTR each (Freyhult et al., 2005; Gruber et al., 2015). 

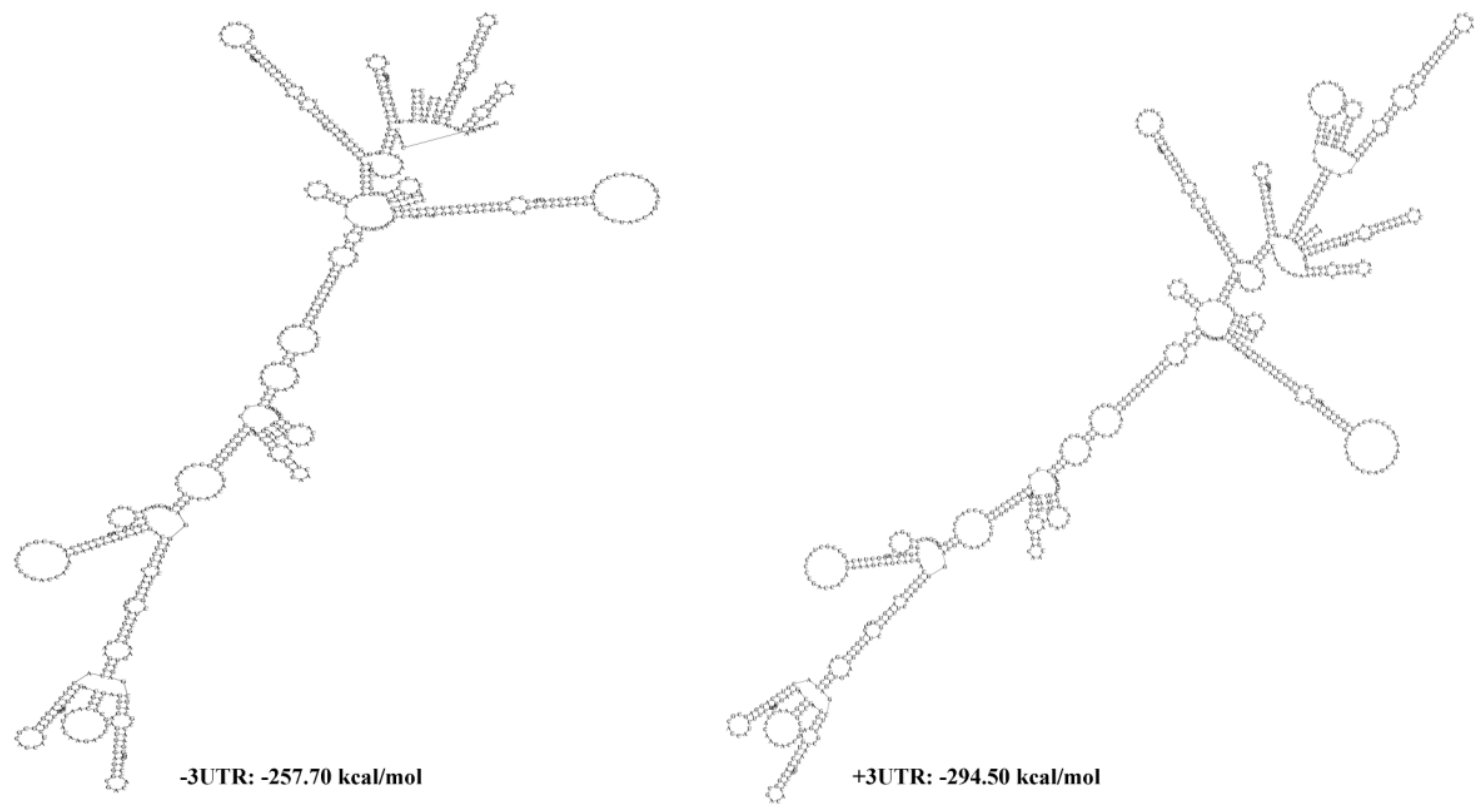

Figure No. 2

RNA secondary structure prediction based on MFE. Sequences from both -3UTR (A) and +3UTR (B) constructs were subjected to prediction of secondary structure by RNA fold Web Server (http://rna.tbi.univie.ac.at/cgi-bin/RNAfold.cgi)

Expression of EGFP was higher in the BHK cell line in the presence of 3'UTR

Flow cytometry was performed to investigate the effect of 3'UTR of the EMCV on the amount of protein production, 24 hours after transfection of BHK cells. As seen in the Figure No. 3, the number of EGFP expressing cells in transfected cells with +3 UTR was slightly higher than -3UTR. More importantly, the geometric mean of these data showed that the mean of fluorescence intensity (MFI) of the cells transfected with +3UTR was greater than -3UTR. The statistical analysis of geometric mean showed a significant difference between the two groups $(p=0.0351)$.

3'UTR did not increase the expression of EGFP in $\mathrm{CHO}$

24 hours after the transfection of $\mathrm{CHO}$ cells with either $+3 \mathrm{UTR}$ or $-3 \mathrm{UTR}$ plasmids, flow cyctometry analysis was performed to investigate the effects on the amount of protein production. As seen in the Figure No. 4, the number of EGFP expressing cells was slightly higher in transfected cells with +3 UTR. However, the geometric mean of these data did not show a significant difference between goroups $(p=0.9)$. 
A
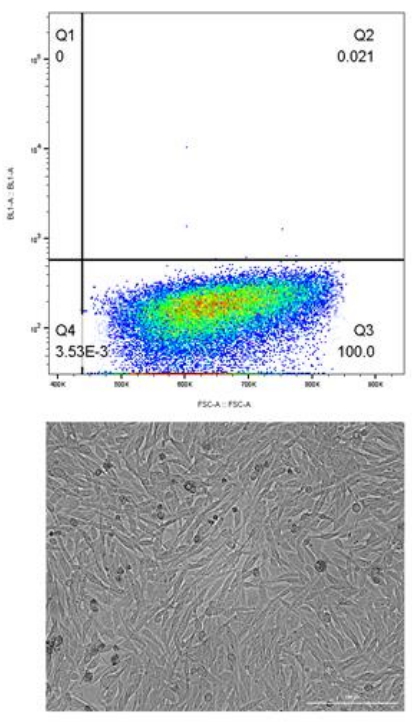

UNTRANSFECTED BHK
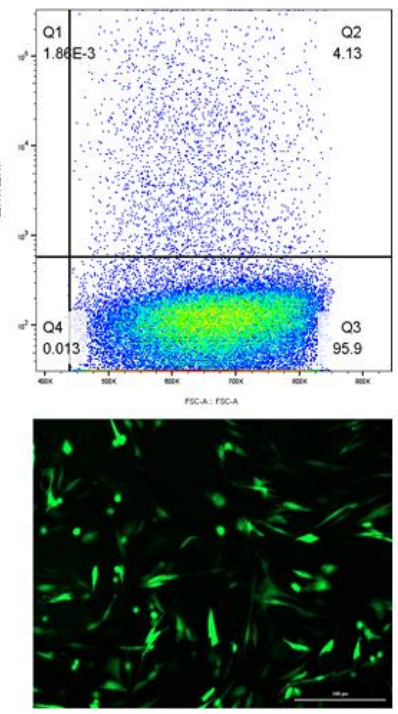

PEGFPN1
B
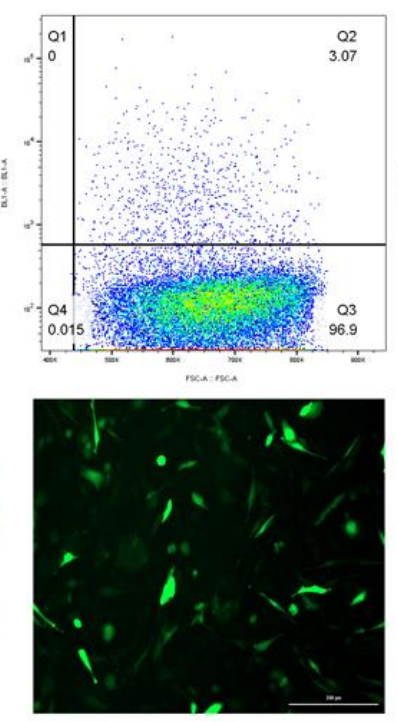

+3 UTR
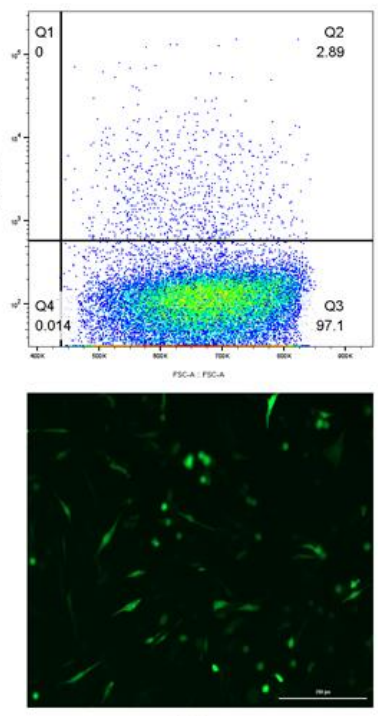

$-3 U T R$

C

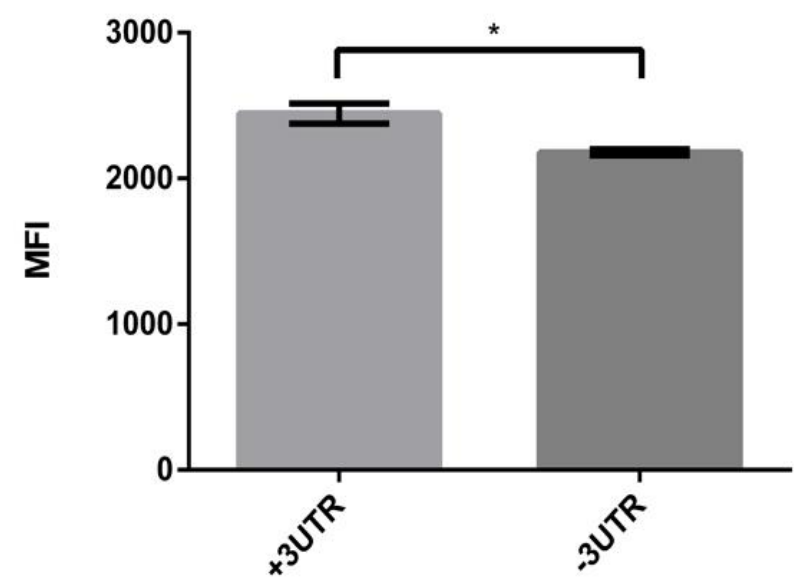

Figure No. 3

Protein expression analysis based on flow cytometry in BHK cell line. A) Representative graph of BHK transfected with PEGFPN1 as a positive control and untransfected cells as a negative control.

B) Representative graphs of BHK transfected with either +3UTR or -3UTR. The proportion of transfected cells were marginally higher in +3UTR group (3.07\% vs. $2.89 \%)$. C) The geographic mean was significantly higher in +3UTR group $(p<0.05)$. Each experiment was carried out at least in triplicate, (mean \pm SD)

EMCV 3'UTR regulates the stability of $m R N A$ in cell and time-dependent manner

The addition of 3'UTR from the EMCV to the 3' end of the reporter mRNA resulted in a significant increase in the relative abundance of EGFP mRNA in the $\mathrm{CHO}$ cell line. This increase was more pronounced at 2,4 and 8 hours in the +3 UTR group, but by reaching 12 hours, the relative abundance of the mRNA of the two constructs reached approximately equal proportions. At 24 hours, the relative abundance of $+3 \mathrm{UTR}$ mRNA was even lower than that of -3 UTR. A similar pattern was observed at 2, 4 and 8 hours post-transfection for the BHK cell line. However, the difference was not as statistically significant as occurred in the $\mathrm{CHO}$ cell line. The difference between the two cell lines was observed at 24 hours after transfection. In the BHK cell line, the relative abundance of $+3 \mathrm{UTR}$ mRNA 
was increased compared to -3UTR mRNA (Figure No. 5). Analysis of variance showed that the addition of 3'UTR sequence from EMCV increases the stability of the transcript in a time and cell linedependent manner.
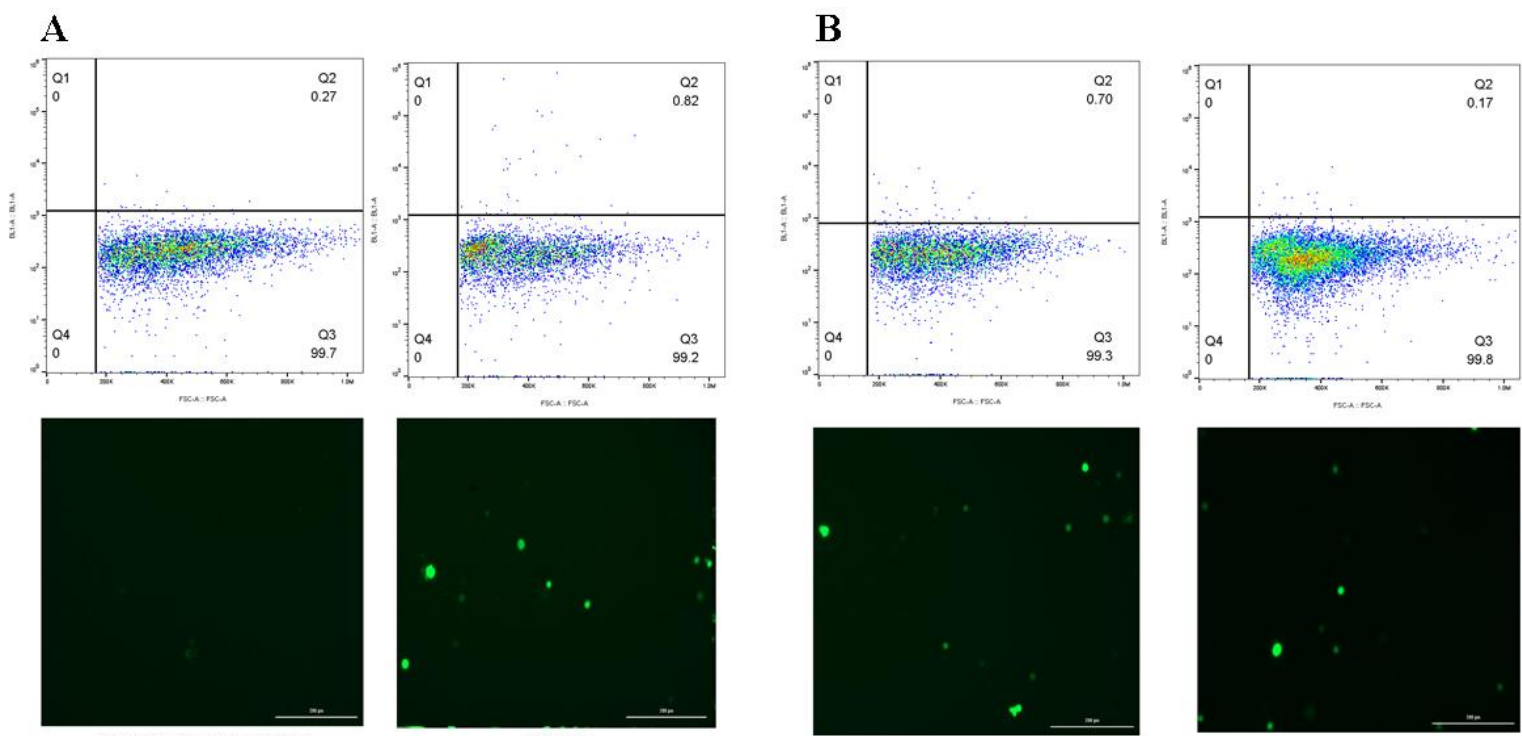

C
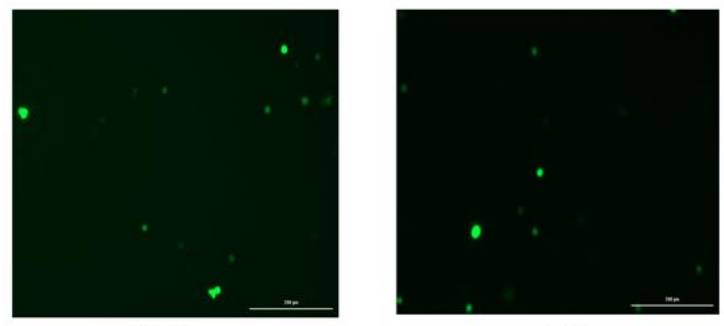

+3UTR

-3 UTR

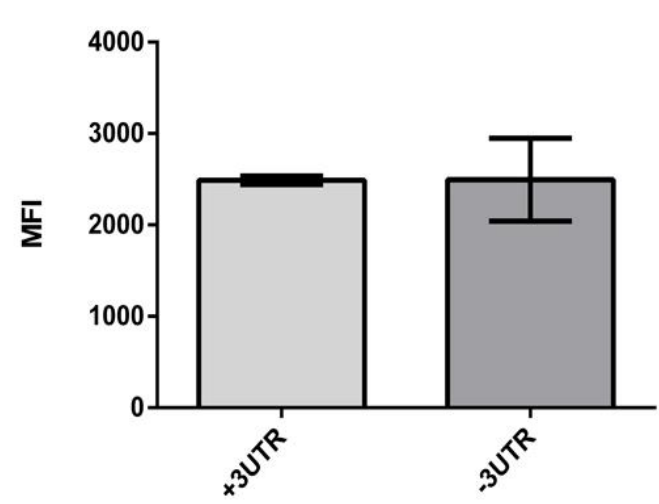

Figure No. 4

Protein expression analysis based on flow cytometry in CHO cell line. A) Representative graph of CHO transfected with PEGFPN1 as a positive control and untransfected cells as a negative control. B) Representative graphs of CHO transfected with either +3UTR or -3UTR. The proportion of transfected cells were marginally higher in +3 UTR group $(0.7 \%$ vs. $0.17 \%)$. C) The geographic mean was not significantly different in between the two groups $(p>0.05)$. Each experiment was carried out at least in triplicate, $($ mean \pm SD) 


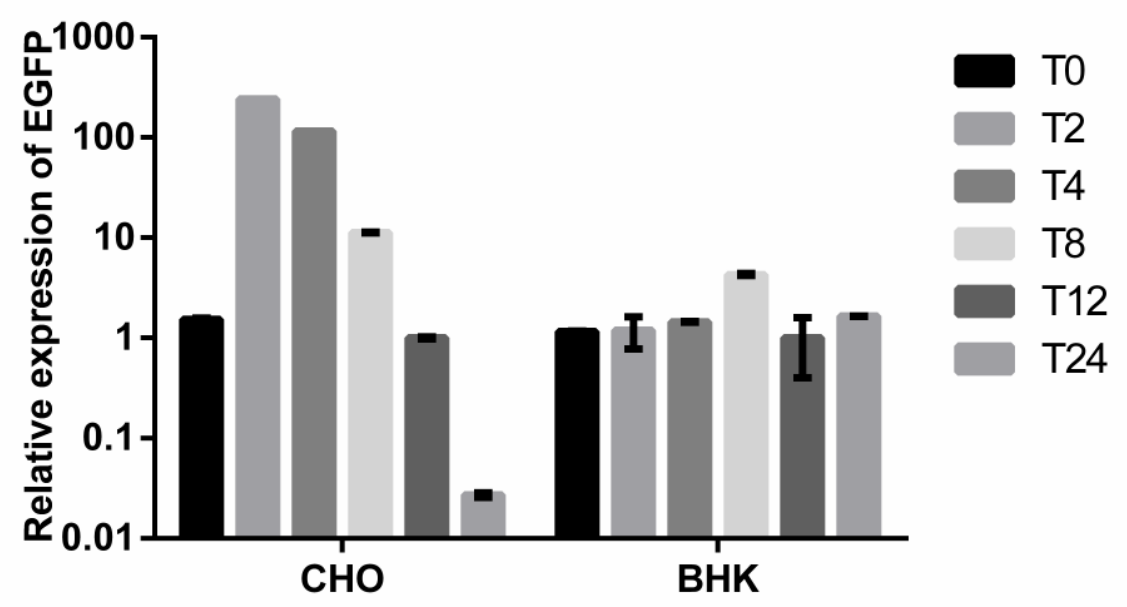

Time fter transfection

Figure No. 5

Caption: Comparison of the relative abundance of EGFP mRNA at different times in BHK and CHO. After transfection of the cell lines with either +3 utr or -3 utr constructs, at specified times RNA extraction was performed. using the specific primers, the relative abundance of EGP mRNA was calculated using the 2- $\Delta \Delta C T$ method

\section{DISCUSSION}

In the present study, the effect of the 3'UTR sequence of EMCV on the expression of an indicator protein (EGFP) was analyzed. The results have shown that EMCV 3'UTR could increase the stability of the transcript albeit, in time and cell-dependent manner in $\mathrm{CHO}$ and BHK cell lines. The change in mRNA stability resulted in an increase in the expression of the reporter protein in the BHK cell line.

The production of sufficient quantities of a new recombinant protein to perform the necessary preclinical studies in the shortest time and with the maximum amount possible is one of the priorities of the pharmaceutical biotechnology industry (Chiou et al., 2014; Gutierrez-Granados et al., 2018; Arenas et al., 2019). At present, a variety of strategies have been used to increase the efficiency of the transient production of recombinant proteins, including the increase of transcript stability (Liu et al., 2017). Transcript stability is a result of the balance between RNA production and decay (Ross, 1995). RNA structural motifs present in the 3'UTR sequences, have an recognized role in determining the RNA stability (Matoulkova et al., 2012). Since the genetic material of RNA viruses are in a constant battle with
RNA surveillance machinery of eukaryotic cells, it can be hypothesized that these pathogens could be a very diverse source of such genetic elements (cis elements) and should be investigated more widely to find RNA stabilizing elements.

Cis elements carry out their effect through interaction with trans acting elements, e.g. miR and RBP. In this sense, the evaluation of EMCV 3'UTR by http://rbpdb.ccbr.utoronto.ca/ predicted that EMCV 3'UTR is a target of ZRANB2 (Zinc Finger Ran-Binding Domain-Containing Protein 2) and RBMY1A1 (RNA binding motif protein, Y-linked, family 1, member A1) (Table No. 1). ZRANB2 is a splicing protein whose specific endogenous targets are still unknown. Alternative splicing is a major source of protein diversity in eukaryotic organisms and is often regulated in a tissue or developmental stage-specific manner (Yang et al., 2013). Although we did not investigate the expression of ZRANB2 in $\mathrm{BHK}$ and $\mathrm{CHO}$ cell lines, the different expression levels of this protein in the two cell lines may lead to different patterns of alternative splicing and EGFP expression (Figure No. 4 and Figure No. 5). RBMY1A1, another candidate RBP to connect to EMCV 3'UTR, is also an active protein in the 
alternative splicing. However, it has been reported that RBMY1A1 plays its role in spermatogenesis and its level of expression in tissues other than the testis is very low (Chua et al., 2015).

miRNAs are short, noncoding RNAs whose dysregulation has been implicated in many types of cancer (Chen et al., 2012; Feng et al., 2018; Anvarnia et al., 2019). They regulate gene expression by suppressing mRNA translation and reducing mRNA stability. To this end, there is a great deal of interest in modifying miRNA expression levels for the treatment of cancer (Svoronos et al., 2016). The results from http://vita.mbc.nctu.edu.tw/ showed that EMCV 3'UTR is a predicted target for mir-339$5 p$ and miR-151-3p (Table No. 2). miR-339-5p has been identified as a regulator of the p53 pathway (Jansson et al., 2015). It has been demonstrated that this regulation occurs via the ability of miR-339-5p to target directly the 3'-untranslated region of MDM2 mRNA, reducing MDM2 expression and thus, promoting p53 function (Jansson et al., 2015). Studies have shown that the expression of miR-339$5 p$ is down-regulated in several cancer types and cancerous cell lines, including colorectal, breast and lung (Wu et al., 2010; Zhou et al., 2013; Li et al., 2018).

According to findings by Ling-Ming Tseng et al. (Yeh et al., 2016), miR-151-3p directly regulates TWIST1 expression by targeting the TWIST1 (a basic helix-loop-helix domain-containing transcription factor) 3'UTR and, consequently, represses the migration and invasion of human breast cancer cells by enhancing E-cadherin expression (Yeh et al., 2016). Twist1 is expressed in breast, liver, prostate, gastric and other types of cancers, and its expression is usually associated with invasive and metastatic cancer phenotypes. Twist 1 significantly enhances epithelial-mesenchymal transition (EMT) and cancer cell migration and invasion, hence promoting cancer metastasis (Qin et al., 2012). Although in the present study the expression of miR339-5p and miR-151-3p in CHO and BHK was not explored, due to the continuous nature of these cell lines, we expect that the miR expression profile resembles cancerous tissue. In addition, the fact that the expression of EGFP in the presence of 3'UTR has not been suppressed, could indicate the down regulation of miR-339-5p and miR-151-3p in the cell lines under investigation.

In this study, the role of 3'UTR EMCV in the expression of the EGFP was also examined. For this purpose, two plasmids were designed, with the only difference being the presence of 3'UTR EMCV at the 3 ' end of the EGFP coding sequence (Figure No. 1). A similar strategy has already been used to evaluate the effect of 3'UTR viruses such as polio virus and rabies virus (Palusa et al., 2012; Rasekhian et al., 2014). Since most marketed biopharmaceutical products have been produced in Chinese hamster ovary (CHO) cells and baby hamster kidney cells (BHK-21) (Zhu, 2012; Dumont et al., 2016) we set out to compare the expression of +3UTR and -3UTR in these two cell lines. The results showed a significant difference between the expression of EGFP between the control plasmid (-3UTR) and +3 UTR in the BHK cell line (Figure No. 3), but the same pattern was not observed in the $\mathrm{CHO}$ cell line. Although these two cell lines are among the most applied cell lines in the production of recombinant proteins, there is no exhaustive study about their proteome and microRNA expression pattern. For this reason, we were not able to attribute the observed results to differential proteome or microRNA expression pattern of these cell lines.

The prediction of the secondary structure of RNA based on MFE is one of the routine methods for estimating the RNA stability and its structure. The predicted MFE for +3 UTR and -3UTR suggested a more stable structure for +3UTR. However, after normalization, this difference reached the minimum. In addition, results from RT-PCR showed that the pattern of RNA stability was different between the two cell lines. The addition of EMCV 3'UTR to the end of EGFP mRNA greatly increased its number in the early hours after transfection compared to control mRNA in CHO. However, at 24 hours after transfection, the number of mRNA +3UTR reached about 0.02 of that of -3 utr mRNA, which suggests a very rapid degradation of +3UTR mRNA after 12 hours post-transfection. The results obtained from flow cytometry also show no significant differences between these two mRNA after 24 hours. However, with regard to the BHK cell line, despite the fact that at all time points after transfection, the number +3UTR mRNA was higher than -3UTR mRNA, this difference was not significant except 8 hours after transfection. After 24 hours, the differences reached about 1.5 times and were confirmed by flow cytometry analysis. Given that the MFE of the two structures are not significantly different, thermodynamic stability cannot further explain the observed difference in mRNA abundance and protein expression. The observed difference can be attributed to the reaction between EMCV 3'UTR and miRs. 
According to findings of a previous research (O'Brien et al., 2018), upon binding of miR to its target sequence on mRNA, RNA-induced silencing complex (RISC) is recruited. Based on the percentage of the complementary between miR and mRNA, the activity of this complex will lead to the termination of translation or destruction of mRNA. Therefore, it can be hypothesized that the observed difference after $8 \mathrm{~h}$ is due to the reaction of +3UTR mRNA and miR.

Previous studies have shown the importance of secondary structures present at the 3'UTR of the of enterovirus in the replication process. Their 5'- and 3'-UTRs fold into many secondary and tertiary structures due to base pairing, giving rise to stemloops (SLs), clover-like structures, or pseudoknots
(PKs), as well as internal ribosome entry site (IRES) elements (Witwer et al., 2001; Zoll et al., 2009). The addition of the 3'UTR EMCV to the end of the reporter gene changes its mRNA stability with a pattern dependent on cell type and time. This change in stability leads to a change in the levels of gene expression. We suggest that more comprehensive studies be carried out on EMCV 3'UTR and in order to design cell lines-specific vectors for in the transient expression of recombinant proteins. In sum, the data obtained from this study indicate that viral genetic elements can be used to design the expression vectors for cell lines most commonly used in the production of recombinant proteins, with the aim of increasing production efficiency.

\section{REFERENCES}

Anvarnia A, Mohaddes-Gharamaleki F, Asadi M, Akbari M, Yousefi B, Shanehbandi D. 2019. Dysregulated microRNAs in colorectal carcinogenesis: New insight to cell survival and apoptosis regulation. J Cell Physiol 234: 21683 - 21693. https://doi.org/10.1002/jcp.28872

Arena TA, Chou B, Harms PD, Wong AW. 2019. An anti-apoptotic HEK293 cell line provides a robust and high titer platform for transient protein expression in bioreactors. MAbs 1 - 10.

https://doi.org/10.1080/19420862.2019.1598230

Bassani M, Beer C, Hesse F, Wirth M, Wagner R. 2014. Optimizing the transient transfection process of HEK-293 suspension cells for protein production by nucleotide ratio monitoring. Cytotechnology 66: 493 - 514. https://doi.org/10.1007/s10616-013-9601-3

Chen PS, Su JL, Hung MC. 2012. Dysregulation of microRNAs in cancer. J Biomed Sci 19: 90. https://doi.org/10.1186/1423-0127-19-90

Cheng J, Maier KC, Avsec Z, Rus P, Gagneur J. 2017. Cis-regulatory elements explain most of the mRNA stability variation across genes in yeast. Rna 23: 1648 - 1659. https://doi.org/10.1261/rna.062224.117

Chiou HC, Vasu S, Liu CY, Cisneros I, Jones MB, Zmuda JF. 2014. Scalable transient protein expression. Methods Mol Biol 1104: 35 - 55. https://doi.org/10.1007/978-1-62703-733-4_4

Chua HH, Tsuei DJ, Lee PH, Jeng YM, Lu J, Wu JF, Su DS, Chen YH, Chien CS, Kao PC, Lee CN, Hu RH, Ni YH, Chang MH. 2015. RBMY, a novel inhibitor of glycogen synthase kinase 3beta, increases tumor stemness and predicts poor prognosis of hepatocellular carcinoma. Hepatology 62: 1480 - 1496. https://doi.org/10.1002/hep.27996

Dumont J, Euwart D, Mei B, Estes S, Kshirsagar R. 2016. Human cell lines for biopharmaceutical manufacturing: history, status, and future perspectives. Crit Rev Biotechnol 36: 1110 - 1122. https://doi.org/10.3109/07388551.2015.1084266

Feng Y, Bai F, You Y, Bai F, Wu C, Xin R, Li X, Nie Y. 2018. Dysregulated microRNA expression profiles in gastric cancer cells with high peritoneal metastatic potential. Exp Ther Med 16: 4602 - 4608. https://doi.org/10.3892/etm.2018.6783

Fields BN, Knipe DM. 1991. Fundamental virology. Lippincott Williams \& Wilkins, Philadelphia, USA.

Freyhult E, Gardner PP, Moulton V. 2005. A comparison of RNA folding measures. BMC Bioinformatics 6: 241. https://doi.org/10.1186/1471-2105-6-241

Garcia-Moreno M, Jarvelin AI, Castello A. 2018. Unconventional RNA-binding proteins step into the virus-host battlefront. Wiley Interdiscip Rev RNA 9: e1498. https://doi.org/10.1002/wrna.1498

Girard P, Derouazi M, Baumgartner G, Bourgeois M, Jordan M, Jacko B, Wurm FM. 2002. 100-liter transient transfection. Cytotechnology 38: 15 - 21. https://doi.org/10.1023/A:1021173124640

Green MR, Sambrook J. 2012. Molecular cloning. A Laboratory Manual, New York, USA. 
Gruber AR, Bernhart SH, Lorenz R. 2015. The ViennaRNA web services. Methods Mol Biol 1269: 307 - 326. https://doi.org/10.1007/978-1-4939-2291-8_19

Gutierrez-Granados S, Cervera L, Kamen AA, Godia F. 2018. Advancements in mammalian cell transient gene expression (TGE) technology for accelerated production of biologics. Crit Rev Biotechnol 38: 918 - 940. https://doi.org/10.1080/07388551.2017.1419459

Jansson MD, Damas ND, Lees M, Jacobsen A, Lund AH. 2015. miR-339-5p regulates the p53 tumor-suppressor pathway by targeting MDM2. Oncogene 34: 1908 - 1918. https://doi.org/10.1038/onc.2014.130

Jin YN, Schlueter PJ, Jurisch-Yaksi N, Lam P-Y, Jin S, Hwang WY, Yeh J-RJ, Yoshigi M, Ong S-E, Schenone M, Hartigan CR, Carr SA, Peterson RT. 2018. Noncanonical translation via deadenylated 3' UTRs maintains primordial germ cells. Nat Chem Biol 14: 844 - 852. https://doi.org/10.1038/s41589-018-0098-0

Khan S, Ullah MW, Siddique R, Nabi G, Manan S, Yousaf M, Hou H. 2016. Role of recombinant DNA technology to improve life. Int J Genomics 2016: 2405954. https://doi.org/10.1155/2016/2405954

Kim TK, Eberwine JH. 2010. Mammalian cell transfection: the present and the future. Anal Bioanal Chem 397: 3173 - 3178. https://doi.org/10.1007/s00216-010-3821-6

Li P, Liu H, Li Y, Wang Y, Zhao L, Wang H. 2018. miR-339-5p inhibits lung adenocarcinoma invasion and migration by directly targeting BCL6. Oncol Lett 16: 5785 - 5790. https://doi.org/10.3892/ol.2018.9376

Liu Y, Beyer A, Aebersold R. 2016. On the dependency of cellular protein levels on mRNA abundance. Cell 165: 535 - 550. https://doi.org/10.1016/j.cell.2016.03.014

Livak KJ, Schmittgen TD. 2001. Analysis of relative gene expression data using real-time quantitative PCR and the 2- $\Delta \Delta$ CT method. Methods 25: $402-408$.

Matoulkova E, Michalova E, Vojtesek B, Hrstka R. 2012. The role of the 3' untranslated region in posttranscriptional regulation of protein expression in mammalian cells. RNA Biol 9: 563 - 576. https://doi.org/10.4161/rna.20231

O'Brien J, Hayder H, Zayed Y, Peng C. 2018. Overview of microRNA biogenesis, mechanisms of actions, and circulation. Front Endocrinol (Lausanne) 9: 402. https://doi.org/10.3389/fendo.2018.00402

Palusa S, Ndaluka C, Bowen RA, Wilusz CJ, Wilusz J. 2012. The 3' untranslated region of the rabies virus glycoprotein mRNA specifically interacts with cellular PCBP2 protein and promotes transcript stability. PLoS One 7: e33561. https://doi.org/10.1371/journal.pone.0033561

Patrushev LI, Kovalenko TF. 2014. Functions of noncoding sequences in mammalian genomes. Biochemistry (Mosc) 79: 1442 - 1469. https://doi.org/10.1134/S0006297914130021

Qin Q, Xu Y, He T, Qin C, Xu J. 2012. Normal and disease-related biological functions of Twist1 and underlying molecular mechanisms. Cell Res 22: 90 - 106. https://doi.org/10.1038/cr.2011.144

Rasekhian M, Roohvand F, Teimoori-Toolabi L, Amini S, Azadmanesh K. 2014. Application of the 3'-noncoding region of poliovirus RNA for cell-based regulation of mRNA stability: implication for biotechnological applications. Biotechnol Appl Biochem 61: 699 - 706. https://doi.org/10.1002/bab.1218

Ross J. 1995. mRNA stability in mammalian cells. Microbiol Rev 59: 423 - 450

Svoronos AA, Engelman DM, Slack FJ. 2016. OncomiR or tumor suppressor? The duplicity of microRNAs in cancer. Cancer Res 76: 3666 - 3670. https://doi.org/10.1158/0008-5472.CAN-16-0359

Witwer C, Rauscher S, Hofacker IL, Stadler PF. 2001. Conserved RNA secondary structures in Picornaviridae genomes. Nucleic Acids Res 29: 5079 - 5089. https://doi.org/10.1093/nar/29.24.5079

Wu ZS, Wu Q, Wang CQ, Wang XN, Wang Y, Zhao JJ, Mao SS, Zhang GH, Zhang N, Xu XC. 2010. MiR-339-5p inhibits breast cancer cell migration and invasion in vitro and may be a potential biomarker for breast cancer prognosis. BMC Cancer 10: 542. https://doi.org/10.1186/1471-2407-10-542

Yang YH, Markus MA, Mangs AH, Raitskin O, Sperling R, Morris BJ. 2013. ZRANB2 localizes to supraspliceosomes and influences the alternative splicing of multiple genes in the transcriptome. Mol Biol Rep 40: 5381 - 5395. https://doi.org/10.1007/s11033-013-2637-9

Yeh TC, Huang TT, Yeh TS, Chen YR, Hsu KW, Yin PH, Lee HC, Tseng LM. 2016. miR-151-3p Targets TWIST1 to repress migration of human breast cancer cells. PLoS One 11: e0168171. https://doi.org/10.1371/journal.pone.0168171

Zhou C, Liu G, Wang L, Lu Y, Yuan L, Zheng L, Chen F, Peng F, Li X. 2013. MiR-339-5p regulates the growth, colony formation and metastasis of colorectal cancer cells by targeting PRL-1. PLoS One 8: e63142. https://doi.org/10.1371/journal.pone.0063142

Boletín Latinoamericano y del Caribe de Plantas Medicinales y Aromáticas/553 
Zhu J. 2012. Mammalian cell protein expression for biopharmaceutical production. Biotechnol Adv 30: 1158 1170. https://doi.org/10.1016/j.biotechadv.2011.08.022

Zoll J, Heus HA, van Kuppeveld FJ, Melchers WJ (2009) The structure-function relationship of the enterovirus 3'UTR. Virus Res 139: 209 - 216. https://doi.org/10.1016/j.virusres.2008.07.014 